\title{
Youth Sexual Offending: Context, Good-Enough Lives, and Engaging With a Wider Prevention Agenda
}

\author{
Stephen Smallbone ${ }^{1}$, Susan Rayment-Mchugh ${ }^{2}$, \& Dimity Smith ${ }^{2}$ \\ ${ }^{1}$ Griffith University \& ${ }^{2}$ Griffith Youth Forensic Service - Neighbourhoods Project
}

\section{Abstract}

In this article we reflect on developments in our thinking and practice concerning youth sexual offending. We put the case that context is critical to understanding and responding to the problem, and accordingly that a social ecological model provides the most suitable conceptual and practice framework for clinical efforts with this population. We argue that, since the primary goal of clinical forensic intervention is to prevent recidivism, clinical efforts should focus on a limited number of specific individual, situational, and ecological risk and protective factors. Finally, we describe how our clinical fieldwork has led to the discovery of serious endemic problems with youth sexual violence and abuse in two different communities, and outline our approach to designing, implementing and evaluating a suite of locally-tailored preventive interventions to reduce the prevalence and impact of these problems.

\section{Keywords}

Juvenile sexual offenders, sexually abusive youth, youth sexual offending, sexual offender treatment, social ecology of sexual abuse, field-based practice, sexual abuse prevention

In this article we reflect on developments in our thinking and practice concerning youth sexual offending. In doing so we develop three arguments: 1) context is critical in conceptualizing and responding to the problem; 2) clinicians should be circumspect about the goals of clinical forensic intervention - so long as recidivism can be prevented or reduced, "good-enough" lives are good enough; and 3) field-based clinical practice allows for direct observation of the ecological context of youth sexual offending, and thereby presents important opportunities to engage with a wider prevention agenda.

\section{Context, Context, Context}

Conventional thinking and practice concerning youth sexual offending has its historical roots in psychiatric and clinical psychological approaches to adult sexual offending. Clinical services for youth sexual offenders proliferated from the late 1980s, and were originally based on models developed for their adult counterparts. Thus specialized, intensive, long-term, group-based treatment programs became the accepted practice standard for youth sexual offenders (American Academy of Child and Adolescent Psychiatry, 2000; National Task Force on Juvenile Sexual Offending, 1993).

A central feature of this clinical model was its more or less exclusive focus on individual-level explanations, assessments, and interventions. It was not just the offending behavior that was seen as unusual and problematic - the young offender himself ${ }^{1}$ was presumed to possess some kind of enduring deficit, disorder, or dysfunction that caused the offending behavior, and that distinguished him from his non-sexual-offending peers. Intensive, specialized

1 We use the male pronoun when referring to sexual offenders in this article. We acknowledge that females comprise a small proportion of sexual offenders. psychological treatment was therefore needed to change these presumed individual-level disturbances.

It was not until the mid-2000s that the use of adult sexual offender models for youth sexual offenders came to be widely questioned (Letourneau \& Miner, 2005; Zimring, 2004; though see also Chaffin \& Bonner, 1998, for an earlier critique). Many programs now give more emphasis to the developmental context of youth sexual offending, and some now also include attention to family and peer relationships. Most modern programs nevertheless retain many of the core features of adult offender interventions. For example, although programs may now highlight the importance of engaging with the youth offender's parents or other guardians, the rationale for doing so often seems to be to strengthen or support the focus on individual-level treatment goals, rather than to target relevant family-level factors themselves. Similarly, a key rationale for groupbased treatment is that this format supposedly provides for a focus on peer-level problems (Worling, 2004). However, few programs seem to directly target actual peer problems that may exist outside the rarified atmosphere of the group therapy room - for example, at school or in the neighborhood.

A particularly notable feature of these conventional approaches is that services are almost always located in centralized clinic or institutional settings. The youth offender client is expected to travel to, or reside in, a central location to gain access to assessment and treatment services. The barriers this may present to the youth client seem to be given little consideration, even though in many cases access problems may lead to non-attendance or exclusion. Many programs have stringent exclusion criteria in the first place (e.g., many will not accept "deniers"), and even then often seem to produce astonishingly high program non-completion rates - as many as $50 \%-70 \%$ of youth sexual offenders accepted into some specialized programs "fail" to complete them (e.g., Becker, 1990; Edwards et al., 2005; Hunter \& Figueredo, 1999; Kraemer, Salisbury, \& Spielman, 1998; Seabloom, Seabloom, Seabloom, Barron, \& Hendrickson, 2003). This is of special concern given evidence that sexual offenders (including youth offenders) who begin but do not complete treatment are more likely to reoffend than are those who don't even begin treatment (Hanson \& Bussiere, 1998; Worling, Litteljohn, \& Bookalam, 2010). From an individual-level perspective, treatment non-completion may conveniently be construed as a personal failure of the youth concerned, rather than as a failure of the treatment providers to take proper account of contextual factors, including the program model itself.

Clinic- and institution-based services also remove the youth sexual offender from his natural family, peer, school, neighborhood and cultural context. In some cases, this may be necessary to ensure the safety of others, but we suspect that in many cases operating services in central locations is simply a matter of convenience for professionals. Conducting clinical observations of the offender outside the context of his normal living environment may inadvertently and artificially frame the problem in terms of the individual offender alone.

\section{Conceptualizing (and Contextualizing) the Problem}

Youth sexual offenders are referred to clinical forensic services typically because of one or more specific incidents of illegal sexual behavior. In fact it is not the sexual behavior itself, but rather the context in which the behavior occurs, that defines the problem. The kinds of sexual motivations and behaviors involved in sexual offenses - desiring physical and sexual contact with others, making sexual overtures, sexual touching, sexual intercourse, and so on - are commonplace, and are almost always socially or at least legally unproblematic. In this respect, sexual offending in most cases can be conceptualized as ordinary sexual behavior enacted in problematic or illegal ways - either without the consent of the other person concerned, with a person under the age of legal consent (including sometimes very young children), with a biological relative (e.g., sibling), or with violence, trickery, or coercion. Sexual offending, by definition, contravenes laws that prohibit sexual behavior in these kinds of specific contexts.

Conceptualizing youth sexual offending as a primarily legal-criminal problem gives recognition to its conceptual and empirical connections to other kinds of crime - sexual offenses, like other kinds of crime, fundamentally involve irresponsible social behavior, rule-breaking, coercion or deception, exploitation of vulnerable others, unrestrained aggression or violence, and so on. Indeed for many youth (and adult) sexual offenders, sexual offending is part of a much broader involvement in an- 
tisocial or unlawful behavior (Smallbone, 2006a Smallbone \& Wortley, 2004). This is a very different way of thinking about the problem than from the conventional psychiatric and clinical psychological perspective that construes sexual offending primarily as a form of sexual psychopathology (see e.g. Laws \& O’Donohue, 2008) - more akin to cross dressing and odd fetishes (which may be perfectly consensual) than to theft, assault, or armed robbery (which by definition are not).

There have, of course, been very significant conceptual and empirical developments outside the clinical sexual offending silo. Arguably, the most relevant and important of these have been in developmental criminology (e.g., Loeber \& Farrington, 1998), environmental criminology (e.g., Wortley \& Mazerolle, 2008), clinical approaches to serious youth antisocial behavior (e.g., Henggeler, Schoenwald, Borduin, Rowland, \& Cunningham, 1998), child maltreatment prevention (e.g., Belsky, 1980) and public health approaches to violence prevention (e.g., Krug, Dahlberg, Mercy, Zwi, \& Lozano, 2002). Far from limiting their focus to the individual characteristics of offenders, the common thread in these approaches is that they situate individual offenders and victims within their natural ecological context. Thus, risk and protective factors are theoretically and empirically located at various levels of the social ecological systems in which the offender and victim develop and live - the same environments, of course, in which the problem behavior occurs. The causes of youth sexual offending therefore exist not just within individual offenders, but also within the family, peer, organizational, neighborhood, and sociocultural systems within which offenders and victims are socially embedded.

According to social ecology theory, the more proximal the system is to the individual concerned, the more direct and therefore more powerful its influence (Bronfenbrenner, 2005). The most proximal elements of any behavior, including sexual offending, are of course those present in the immediate setting in which the behavior is enacted. Recognizing the role played by immediate situational factors adds a crucial element to clinical and wider prevention efforts. Instead of conceptualizing the problem in terms of individuals within their social ecological context, we can conceptualize the problem in terms of person-situation interactions that occur within, and are shaped by, the wider ecological context. Situations include physical features of the setting and in-the-moment interactions between the offender and victim, as well as the presence/absence and behavior of third parties such as guardians, co-offenders, and bystanders.

We accordingly conceptualize youth sexual offending in terms of proximal interactions of individua and situational factors that occur within the wider context of the offender's and victim's social ecology. We have set out our integrated theory in detail elsewhere (see Smallbone, 2006b; Smallbone \& Cale, in press; Smallbone, Marshall, \& Wortley, 2008), and provide only a brief summary of key propositions here.

First, our theory assumes a universal biologically-based potential among adolescent and adult males to engage in sexual violence and abuse (see also Marshall \& Barbaree, 1990). This behavior does not need to be learned because it has been naturally selected in our ancestors' environment of evolutionary adaptedness. Unlike in conventional clinical formulations, for example, the potential to behave in such ways is therefore not confined to a deviant subset of individuals. The reason that comparatively few people actually do commit sexual offenses is because human socialization and social control systems (e.g., personal and social attachments, individual and social controls), together with natural ecological and situational barriers (e.g., guardianship, risk of detection), are under most circumstances remarkably effective in constraining this potential.

Second, our theory points to risk and protective factors at various levels of offenders' and victims' natural social ecologies; that is, the particular family, peer, organizational, neighborhood, and sociocultural systems within which they are socially embedded. For example, although families generally offer the front line of protection to children, family homes are also the most common place for sexual abuse to occur. Youth's peers will often provide important protections (e.g., by looking out for one another), but they may also endanger one another (e.g., by encouraging irresponsible or risky behavior). Similarly, organizational settings such as schools usually provide safe environments for children, but sometimes expose children to risks for peer or adult sexual abuse.

Third, our theory recognizes immediate situations (or, more precisely, immediate person-situation interactions) as the most proximal causes of sexual offending. We construe situations not just as a passive backdrop that presents opportunities to an already-motivated offender, but also as containing highly dynamic properties that can precipitate offense-related motivations that would not otherwise occur, at least not at that particular time or place (Wortley \& Smallbone, 2006). This opens the door to employing situational and place-based strategies as part of the clinical and prevention armory. From an ecological-situational perspective, changing immediate environments themselves is often key to preventing undesirable individual behavior.

Finally, sexual offending behavior, like other operant behavior, is shaped by its consequences and enabled or constrained by its situational determinants. Youth sexual offenders are more likely to commit further such offenses if their early experiences with sexual offending are positively or negatively reinforcing, and if relevant opportunity structures and precipitating conditions continue to be presented. They are less likely to persist if the original incidents were unrewarding, if opportu- nities are blocked or reduced, and if the relevant precipitating conditions are no longer present.

\section{Responding to the Problem}

If, as we argue, youth (and adult) sexual offending is caused by the interaction of individual and situational factors in the context of offenders' and victims' natural social ecologies, it makes sense that clinical assessments and interventions should focus on these three aspects of the problem (i.e., individual, situational, and ecological). The precise mix of appropriate interventions will of course be informed by a careful assessment of the individual, situational, and ecological factors relevant to the particular case, and how these may interact to produce the specific outcome of sexual offending. In many cases, restoring a secure attachment with a parent, enhancing and focusing guardianship, reducing involvement with antisocial peers (or increasing involvement with prosocial peers), removing barriers to school engagement, or reducing exposure to specific risky situations, may be more important than achieving conventional individual-level treatment goals such as overcoming denial, increasing general or victim-specific empathy, or improving general self-regulation. This is not to say that individual-level interventions are irrelevant - on the contrary, in many cases individual-level interventions may be crucial components of the treatment and risk management plan. The point is to understand how individual behavior generally, and sexual offending behavior specifically, is influenced by its social and immediate situational context. Without attending to this context, the goal of individual-level treatment may amount to little more than trying to make the youth offender somehow resistant to what may be powerful criminogenic influences in his living environment.

Multisystemic therapy (MST) provides a proven model for addressing individual and systemic factors known to be associated with serious antisocial behavior (Henggeler, et al., 1998), and in fact MST has been shown to be effective specifically with youth sexual offenders (Borduin, Schaeffer \& Heiblum, 2009; Letourneau et al., 2009). However, MST is an intensive, family-based treatment and may not be readily transferable to institutional settings (in fact, it is often promoted as a community-based alternative to youth detention) or to community settings where clinicians cannot be present or available on a continuous basis. Family-based treatment is also clearly problematic in circumstances where there are severe breakdowns in the youth offender's family relationships. Nevertheless, MST's strong conceptual and empirical foundations, even if not its prescribed methods, may provide clear direction to clinicians in the diverse range of circumstances in which they may be working with youth sexual offenders.

In our own case, we provide court-ordered assessments and interventions both in institutional (youth detention) settings and in a diverse range of community settings. We give priority to cases ini- 
tially assessed as high risk (in accordance with the so-called risk principle), and to cases from regional and remote locations (because alternative services are least likely to be available in these locations). Of the more than 400 youth referred to our service over the past 12 years, $82 \%$ were serving community youth justice orders (i.e., only $18 \%$ were serving detention orders), requiring treatment to be provided in the community rather than in institutional settings. This is in large part the result of concerted efforts by Australian legislators, courts, and youth justice authorities over the last two decades to use detention only as a last resort for youth offenders. By far the bulk of our assessments and interventions are therefore conducted in community settings, including with very complex-needs, highrisk offenders, and sometimes in geographically difficult-to-reach places.

Ours is a state-wide field-based service, covering a vast geographical region of more than 1.85 million square kilometers - an area larger than Alaska and with a population of about 4.5 million. Our client population is small, geographically dispersed and culturally diverse. More than one third (37\%) of our referrals have involved Aboriginal or Torres Strait Islander (Australian Indigenous) youth and their families, and $27 \%$ of these resided in remote or very remote locations (as rated by the Accessibility/Remoteness Index of Australia). Clearly, it would not be possible in these circumstances to provide the kind of continuous, intensive intervention prescribed by MST. Instead, significant modifications have been needed to develop an ecological practice model suitable to our particular geographical and social context.

Our response to the challenge of providing specialized interventions in regional and remote locations has been to establish a system of local collaborative partnerships (see Smallbone, Rayment-McHugh Crissman, \& Shumack, 2008). These may be informal (e.g., with parents, extended family members, or other responsible community members) or formal (e.g., with local professionals and paraprofessionals), and are organized according to the circumstances of each individual case.

Collaborative partnerships involve much more than simply the sharing of information or the co-ordination of otherwise disparate efforts; rather, the work involves focusing and systematic monitoring of specific tasks in accordance with individualized treatment and risk management plans. The great advantage of working with local partners is that they bring crucial local knowledge and leverage, as well as enabling a continuity of intervention that would not otherwise be possible. An especially valuable contribution, particularly in remote indigenous communities, has been advice on local cultural matters that might otherwise present an impenetrable barrier to visiting non-indigenous professionals. For our part, along with the expertise we hope to bring to bear on individual cases, we aim to impart specialist knowledge and skills that may build local capacity to prevent or respond to similar problems in the future.

This field-based model, whereby our clinicians travel to the client (rather than vice versa), along with the ecological framework that guides our assessments and interventions, we believe preserves the ecological validity of assessments and interventions in ways that centralized clinic-based practice simply cannot. Spending time "on the ground" in our clients' communities, meeting with families in their own homes or neighborhoods, engaging with local community leaders and service providers, and so on, allows us to directly observe the ecological context in which the offending has occurred, and in which the risk of further offending is most relevant. Recruiting local collaborative partners and working with the youth offender himself within his own community in turn allows for treatment and risk management interventions to occur in the setting that is most relevant to the youth concerned.

\section{Continual Expansion of the Sexual Offender Treatment Model}

In the previous section we raised a number of problems, as we see them, with conventional clinical approaches to youth sexual offending, namely: (a) the creation of a sexual offending clinical and research "silo" wherein youth sexual offending has been conceptually linked to adult sexual offending, with little attention given to its obvious conceptual and empirical connections with general delinquency, crime, and violence; (b) a narrow focus on individual-level explanations and interventions that is out of step with developments in closely related fields; and, (c) a system of centralized service delivery that may optimize convenience for service providers, but also creates serious barriers for clients and diminishes the ecological validity of clinical services. Another major problem with this conventional approach, which again came with the ill-considered transposition of adult sexual offender clinical models to work with youth sexual offenders, is the seemingly ever-increasing length and complexity of these individual-level treatment programs.

Laws and Marshall (2003) and Marshall and Laws (2003) outlined a history of cognitive behavioral approaches to sexual offending. Their historical account begins with the application of simple behavioral methods (e.g., aversive conditioning) in the 1950s and 1960s, through the addition in the 1970s of cognitive therapy components (targeting offense-related attitudes and beliefs, cognitive distortions, rationalizations, assertiveness, and social skills), and culminating in the 1990s with the so-called "comprehensive" treatment program models. In addition to the earlier treatment targets, Marshall and Laws listed sex education, empathy, relationship skills, self-esteem, substance abuse, anger management, and relapse prevention as further points of focus in comprehensive programs. To this already-extensive list, even more treatment targets were added in the 1990s, such as attachment problems, intimacy deficits, sexual coping, denial, and implicit theories. Marshall and Laws described these trends as "a continuous expansion in treatment and assessment targets" (p. 98), and saw the adoption of these models for youth sexual offenders as part of the natural and proper progression of the field.

However, a big problem with this history of thinking and practice is that, while there has been no shortage of new ideas and techniques, these have almost always been promoted as additions to, rath er than as replacements for, previous approaches. Progress has thus been characterized by accumulation, rather than revision and refinement. The upshot is that while there is now evidence that some such programs do "work" in terms of reducing recidivism (Lösel \& Schmucker, 2005; however see also Långström, et al., 2013 for a less optimistic analysis), it is not at all clear which of the many aspects of these programs produce positive outcomes (and indeed, which components may be ineffective or even harmful). No-one seems to be prepared to discard old ideas or techniques to make way for new approaches.

One of the most influential recent developments in the sexual offending field has been the so-called good lives model (GLM) developed by Ward and his colleagues (e.g., Ward \& Brown, 2004). Early expositions seemed to present the GLM as a viable alternative to the widely accepted and empirically supported Risk-Needs-Responsivity (RNR) model of offender rehabilitation (Andrews \& Bonta, 1998). However, following a round of vehement criticisms, rebuttals, and counter-criticisms from the two camps (see Andrews, Bonta, \& Wormith 2011; Ward, Yates, \& Willis, 2012; Wormith, Gendreau, \& Bonta, 2012), the position of the GLM appears to have been clarified as yet another addition to, and not a replacement of, existing models based on RNR principles.

The major difference between the GLM and earlier developments is that its proposed additions are much more complex and wide-reaching, seeming to amount to a more or less wholesale change in treatment philosophy and purpose. In addition to the RNR goals of preventing recidivism by targeting a limited number of specific, empirically-based, or theoretically valid risk factors, the GLM seems to frame the purpose of clinical treatment with sexual offenders primarily in terms of helping offenders to achieve a "good life", defined as achieving a wide range of personal, interpersonal, and social goals (Willis \& Ward, 2011). Taken at face value, GLM appears to adopt the position that individual-level interventions, even while acknowledging the wider context of relationships and community, stil provide the best path to preventing future sexually abusive behavior. There seems to be no expectation that clinicians assess or intervene directly with the offender's family, peer, organizational or neighborhood systems. 
We do, of course, see merit in the "positive, strengths-based" approach espoused by the GLM. Indeed, we suspect this may be a key reason for its popularity among clinicians who work in otherwise punitive, risk-averse criminal justice or youth justice systems. However, in this respect the GLM seems to offer little that is new. For instance, in terms of work with adolescents, MST also explicitly proposes a strengths-based approach (Henggeler, et al., 1998). The key advantage of MST, though, is its foundation in social ecology theory and an extensive evidence base concerning risk and protective factors associated with serious youth antisocial behavior. For us, a positive, strengths-based approach has always been a key mechanism for engaging with our youth offender clients, families, and relevant others (Smallbone, Crissman, \& Rayment-McHugh, 2009), and we see no incompatibility with maintaining a clear focus on the primary goal of preventing recidivism; indeed, we think it contributes greatly to achieving that goal.

\section{A Good-Enough Lives Model}

A major challenge for us in our own clinical practice with youth sexual offenders has been to find the proper line between under-involvement and over-involvement with individual cases. Many of our youth offender clients present with serious and complex personal and life problems, and we recognize the temptation to take their referral as an opportunity to try to "fix everything." In accordance with the RNR model, we aim in our individualized assessments and case formulations to distinguish between those factors that may be associated with risk for recidivism, and those that may not be - socalled criminogenic and non-criminogenic needs. Where it is feasible to do so we try to refer to other services to attend to serious non-criminogenic needs so that our own work can concentrate on the specific referral problem - the sexual offending behavior. In the context of operating a specialized service with inevitably limited resources, time spent on non-essential work (i.e., work not directly focused on preventing recidivism) is time that could be spent on essential work with other cases. The worst-case scenario would be that we become so preoccupied with "fixing everything" for our existing clients that we cannot accommodate new referrals for other young offenders, which seems to us neither fair nor appropriate. Denying access to services for some offenders so that we can spend additional time on non-essential interventions with existing clients seems to us frankly irresponsible.

We have found the continuous expansion in treatment and assessment targets that has characterized clinical work with sexual offenders a potential distraction from the central goal of preventing recidivism. At the same time, we have found the frequent preoccupation in this field with individual-level problems and interventions as theoretically and professionally impoverished. Our clinical challenge has been to identify and target, on a case by case basis, a limited number of specific individual, situational, and ecological factors associated with the risk for recidivism. We think of our own practice model, somewhat tongue-in-cheek, as a "goodenough lives" model. For us, a "good-enough" life for our youth sexual offender clients is one in which they cause as little harm as possible to others (and indeed to themselves).

\section{- Engaging with a Wider Prevention Agenda}

Our clinical assessments, case formulations, and interventions with referred youth sexual offenders are focused on the specific individual, situational, and ecological factors associated with their risk of sexual (and other serious) recidivism. This work is generally undertaken in the field - in the community in which the offender presently lives (or, for youth in detention, situational and ecological assessments are undertaken in the community to which they will return on release). Our ecological assessments span family-, peer-, organization-, and neighborhood-level factors. In most cases, these assessments point to a circumscribed set of factors associated with the systems most proximal to the youth offender - typically their family and peer systems, but also often including school-level factors. Interventions are accordingly typically directed to these proximal systems. However, occasionally a wider set of neighborhood-level factors is identified as significant. In this section we describe two such circumstances, and explain how we are organizing a prevention initiative that aims to reduce the prevalence and impacts of youth sexual violence and abuse in these two communities.

\section{Identifying Neighborhood-Level Problems}

The first setting of concern is a small, remote $\mathrm{Ab}$ original community. A few years ago we received referrals concerning a number of young males who had been convicted of sexual offenses in this community. All of these referrals were received at the same time - referred youth were co-offenders in a number of incidents. Initial assessments (conducted mainly in the community, but also in detention with two of the youth involved) indicated that the specific incidents for which these young people had been arrested were part of a much more pervasive problem with youth sexual violence and abuse in this community.

Two problems quickly became apparent. First, while it seemed clear that a mix of individual (e.g., general and sexual self-regulation), family (e.g., family violence, low supervision) and peer factors (e.g., attachments to antisocial peers, peer norms supportive of sexual violence) was associated with the problem behavior for each of the young people involved, there were also a number of serious community-level risk factors, including severe breakdowns in local formal and informal social control systems, high levels of neighborhood crime and violence, and low capacity for community guardianship. This was a stark example of how conventional individual-level conceptualizations would miss key aspects of the context of the problem behavior, and how focusing exclusively on individual-level interventions would therefore be patently ineffective.

Second, it was clear that, even if we were successful in preventing further sexual offending by the individual referred youth, clinical interventions with these youth alone would do little to solve the wider community-level problems. Many other young people in this community were clearly at risk of sexual offending or sexual victimization, and we were aware there were likely to be other active but undetected offenders. In any case, it was clear that the individual referred youth would quickly be replaced by other children and young people who had not yet commenced sexual offending but were at high risk of doing so as they grew older and were exposed to the same individual, situational, and ecological risk factors associated with our referred cases.

The second setting of concern is a suburban precinct in a regional city. We had received 19 individual referrals concerning young people residing in this area since 2002. Unlike in the Aboriginal community described above, our awareness of possible endemic community-level problems in this locale developed over a period of some years as the individual referrals accumulated. A review of the 19 individual cases from this area indicated somewhat similar individual-, situational, family-, peer-, school- and neighborhood-level risk factors to those observed in the remote Aboriginal community. On the other hand, because of the different context, there were many different features. Perhaps the most obvious of these was that the problems were nested within an otherwise mainstream urban setting. The striking similarity, though, was that once again it became clear that (a) individual-level intervention alone would not address the wider systemic problems, and (b) many children and young people in this community, other than our individually referred offender clients, were at high risk of sexual offending or victimization if these wider systemic problems were left unaddressed.

In 2011 we obtained funding from our state government to more systematically investigate the scope, dimensions, and dynamics of youth sexual violence and abuse in these two communities. We used a mixed methods approach involving official (police, youth justice, and health) data, file reviews, interviews with local professionals and community members, and direct site observations to identify problem behavior hotspots and hot-times. Due to the sensitivity of our findings, our report is currently subject to a publication embargo and we cannot name the communities or present detailed findings at this stage. Suffice to say here that our analyses confirmed serious problems at both sites, and provided some early direction to the task of designing, implementing, and evaluating specific preventive interventions. 
Table 1. Prevention matrix

\begin{tabular}{|c|c|c|c|}
\hline & Primary Prevention & Secondary Prevention & Tertiary Prevention \\
\hline $\begin{array}{l}\text { Offenders/ } \\
\text { Potential } \\
\text { Offenders }\end{array}$ & $\begin{array}{l}\text { - Reduce exposure to known } \\
\text { developmental risk factors } \\
\text { - Introduce school-based sexual } \\
\text { ethics programs } \\
\text { - Increase school attachment/ } \\
\text { reduce school disengagement }\end{array}$ & $\begin{array}{l}\text { - Re-engage school-disengaged } \\
\text { youth } \\
\text { - Therapeutic services, particularly } \\
\text { for boys exposed to known risk } \\
\text { factors } \\
\text { - School-based support and } \\
\text { intervention with at-risk boys } \\
\text { - Reduce number of new gang } \\
\text { affiliations }\end{array}$ & $\begin{array}{l}\text { - Incapacitate most prolific / serious } \\
\text { youth offenders } \\
\text { - Expand offender rehabilitation } \\
\text { services } \\
\text { - Provide means to exit antisocial } \\
\text { peer groups/ gangs }\end{array}$ \\
\hline $\begin{array}{l}\text { Victims/ } \\
\text { Potential } \\
\text { Victims }\end{array}$ & $\begin{array}{l}\text { - Reduce exposure to known } \\
\text { developmental risk factors } \\
\text { - School-based resilience-building } \\
\text { programs } \\
\text { - Reduce prevalence of school } \\
\text { disengagement }\end{array}$ & $\begin{array}{l}\text { - Interventions with at-risk girls } \\
\text { (personal safety, guardianship, sex } \\
\text { education) } \\
\text { - Increase support and assistance } \\
\text { for marginalized children/youth }\end{array}$ & $\begin{array}{l}\text { - Improve reach and effectiveness } \\
\text { of victim support and treatment } \\
\text { services } \\
\text { - "Cocoon" the most vulnerable } \\
\text { victims } \\
\text { - Focus therapeutic efforts on } \\
\text { preventing re-victimization }\end{array}$ \\
\hline Situations & $\begin{array}{l}\text { - Create safe, attractive places for } \\
\text { children and youth } \\
\text { - Increase legitimate use of public } \\
\text { spaces }\end{array}$ & $\begin{array}{l}\text { - Improve natural surveillance in "at } \\
\text { risk" places } \\
\text { - Increase planned/ legitimate/ } \\
\text { supervised activities in "at risk" } \\
\text { public locations } \\
\text { - Community night patrols targeting } \\
\text { specific problem locations/times } \\
\text { - Targeted problem-oriented and } \\
\text { community policing }\end{array}$ & $\begin{array}{l}\text { - Improve targeting of police patrols } \\
\text { (hot spots; hot times) } \\
\text { - Disrupt problem youth group } \\
\text { activities/ movements } \\
\text { - Disrupt access to alcohol/ } \\
\text { substances } \\
\text { - Target hardening to reduce alcohol } \\
\text { thefts }\end{array}$ \\
\hline Community & $\begin{array}{l}\text { - Mobilize and focus community } \\
\text { concerns about sexual violence } \\
\text { - Parenting programs tailored for } \\
\text { the local context }\end{array}$ & $\begin{array}{l}\text { - Responsible bystander training } \\
\text { (youth and adults) } \\
\text { - Problem-solving with community } \\
\text { leaders to reduce barriers to } \\
\text { community guardianship } \\
\text { - Intensive interventions with multi- } \\
\text { problem families }\end{array}$ & $\begin{array}{l}\text { - Mobilize and focus community } \\
\text { concerns about sexual violence } \\
\text { - Community engagement } \\
\text { focused on improving extended } \\
\text { guardianship } \\
\text { - Appoint school engagement } \\
\text { officers }\end{array}$ \\
\hline
\end{tabular}

\section{Design and Implementation of Prevention Strategies}

In 2013 we were awarded a large grant from the Australian government to design, implement, and evaluate a suite of individual, situational, and ecological interventions aimed at reducing the prevalence and impacts of youth sexual violence and abuse at the two communities of concern. This new project brings a team of researchers and practitioners together with local community members, local non-government organizations, local councils, and key state and federal government agencies, in a focused effort to redress identified problems. The project will draw on public health and crime prevention concepts and methods (Smallbone, Marshall, \& Wortley, 2008), and will be guided by "realist" evaluation principles (Pawson \& Tilley, 1997) whereby interventions aim to address the questions: what works for whom, in what circumstances and in what respects, and how?

Table 1 sets out a comprehensive prevention matrix, together with some examples of the kinds of prevention activities that may target the various aspects of observed problems. As shown in the table, this prevention model directs potential interventions to four essential targets - (potential) offenders, (potential) victims, situations, and communities - across three prevention levels: primary, secondary, and tertiary (see Smallbone et. al., 2008, for a more detailed rationale and discussion of this model). Note that in practice it may be feasible to focus only on a limited number of separate intervention activities, and in this respect the matrix provides a menu of inter-related options rather than a specific prevention plan. Note also that the prevention matrix highlights how clinical interventions with identified offenders (offender-focused, tertiary-level prevention) is but one aspect of prevention. This does not, of course, diminish the importance of clinical work with known offenders (indeed we ourselves place a high value on this work) - it simply situates clinical forensic interventions within a much wider scope of potential prevention activities.

All indications are that, to be successful, preventive interventions in these two communities must be designed and implemented in authentic partnership with the communities themselves. For the earlier research project we established local advisory groups in the two communities to advise on data collection and interpretation and on local cultural and social matters. For the present prevention project these groups will be re-formed, probably with some new members as appropriate, and their role expanded to establish new Local Implementation Groups (LIGs) at both sites. It is in collaboration with these LIGs that decisions will be made about the prioritization of target problems, and the selection and design of specific intervention activities. LIGs will also advise on practical matters concerning opportunities and constraints, access to local resources, and local cultural and social matters.
A prevention plan will be developed for each site, in collaboration with the LIGs. These plans will be informed by "what works" crime prevention research, professional experience, local knowledge, accessibility of suitable resources, and initially by the findings of our earlier research at the two sites. Prevention plans will be continuously monitored and periodically revised as new data are obtained and interim outcomes considered. We anticipate that interventions will include existing evidence-based strategies, as well as innovative evidence-informed strategies as appropriate in the particular circumstances. This will allow us to test the effectiveness of proven approaches in these particular contexts, as well as developing and testing new methods. We aim to implement a minimum of five separate intervention activities at each site, with priority given to interventions likely to have the highest feasibility and potential impact.

As a result of our field-based clinical work in these communities, a network of relevant existing services has already been established in both communities. This network will be maintained and further developed over the course of the prevention project. Members of the project team will work to improve the targeting and effectiveness of these existing services through written agreements, close consultation, monitoring intervention fidelity, supervision, training, and "on the ground" co-ordination. Members of the project team are also likely to be involved in the direct implementation of some interventions (e.g. therapeutic services).

\section{Evaluation}

Our "realist" evaluation model (Pawson \& Tilley, 1997) involves a theory-driven method that requires clarity and explicitness about what each proposed intervention activity is expected to bring about by way of outcomes, in the specific context of the locale for the activity. Relevant data will be defined and specified by expected outcomes and are likely to include quantitative and qualitative data from records, observations, and interviews. These data will be used to monitor both the expected outcomes and the processes through which they were produced, as well as providing information on the conditions necessary for the activities to produce desired outcomes.

We aim to implement the project and disseminate findings in a manner that facilitates the transferability of the prevention model to other sites, and to other related problems. This will be done by evaluating each intervention activity, as well as the prevention model itself, and particularly by identifying likely mechanisms and relevant contextual factors associated with observed outcomes.

\section{- Conclusions}

We have endeavored to present the case that context is crucial to understanding and responding to the problem of youth (and adult) sexual offending. We have argued that the limited focus on individual-level conceptions and interventions in this field 
is out of step with developments in a range of closely related fields. For some decades now, the social ecological framework has dominated thinking and practice in fields such as developmental criminology, environmental criminology, clinical approaches to serious youth antisocial behavior, child maltreatment prevention, and public health approaches to violence prevention. The ecological model has given rise to a wealth of empirical evidence concerning individual, situational, and ecological risk and protective factors associated with crime and violence, and to a range of evidence-informed approaches to crime and violence prevention.

However, clinical approaches with detected sexual offenders seem to have been little influenced by these conceptual, empirical, and practice developments. An important exception has been the application of multisystemic therapy (MST) - an ecological method of clinical intervention originally developed for working with serious antisocial youth - to youth sexual offenders. While we have adopted a similar conceptual framework in our own clinical work with youth sexual offenders, we have found aspects of MST's practice framework unsuitable to our particular circumstances. We have instead developed an ecological, collaborative, field-based practice model whereby our clinicians work with youth offenders, their families, and relevant others, in their local communities.

We believe that our model preserves the ecological validity of clinical assessments and interventions in ways that centralized clinic- or institution-based practice simply cannot. Further, our work in the field has led to the discovery of serious endemic problems associated with youth sexual violence and abuse that likely would otherwise have remained hidden. This has presented opportunities for us to engage with a wider prevention agenda, focused on two specific communities.

There can be no argument that preventing such offenses from occurring in the first place is much more desirable than intervening after such offenses have occurred. It remains to be seen whether our prevention efforts are successful in achieving this.

\section{- REFERENCES}

American Academy of Child and Adolescent Psychiatry. (2000). Summary of the practice parameters for the assessment and treatment of children and adolescents who are sexually abusive of others. Journal of the American Academy of Child and Adolescent Psychiatry, 39, 127-130.

Andrews, D. A., \& Bonta, J. (1998). The psychology of criminal conduct. Cincinnati, $\mathrm{OH}$ : Anderson.

Andrews, D. A., Bonta, J., \& Wormith, J. S. (2011). The Risk-Needs-Responsivity (RNR) model: Does adding the Good Lives Model add to effective crime prevention? Criminal Justice and Behavior, 38, 735-755.

Becker, J. V. (1990). Treating adolescent sexual offenders. Professional Psychology: Research and Practice, 21, 362-365.

Belsky, J. (1980). Child maltreatment: An ecological integration. American Psychologist, 35, 320-335.
Borduin, C. M., Schaeffer, C. M., \& Heiblum, N. (2009). A randomized clinical trial of multisystemic therapy with juvenile sexual offenders: Effects on youth social ecology and criminal activity. Journal of Consulting and Clinical Psychology, 77, 26-37.

Bronfenbrenner, U. (2005). The bioecological theory of human development. In U. Bronfenbrenner (Ed.), Making human beings human: Bioecological perspectives on human development (pp. 3-15). Thousand Oaks, CA: Sage.

Chaffin, M. and Bonner, B. (1998). Don't shoot, we're your children: Have we gone too far in our response to adolescent sexual abusers and children with sexual behavior problems? Child Maltreatment, 3, 314-316.

Edwards, R., Beech, A., Bishopp, D., Erikson, M., Friendship, C., \& Charlesworth, L. (2005). Predicting dropout from a residential programme for adolescent sexual abusers using pre-treatment variables, and implications for recidivism. Journal of Sexual Aggression, 11, 139-155.

Hanson, R. K., \& Bussiere, M. T. (1998). Predicting relapse: A meta-analysis of sexual offender recidivism studies. Journal of Consulting and Clinical Psychology, 66, 348-362.

Henggeler, S. W., Schoenwald, S. K., Borduin, C. M., Rowland, M. D. \& Cunningham, P. B. (1998). Multisystemic treatment of antisocial behavior in children and adolescents. New York: Guilford Press.

Hunter, J. A., \& Figueredo, A. J. (1999). Factors associated with treatment compliance in a population of juvenile sexual offenders. Sexual Abuse: A Journal of Research and Treatment, 11, 49-67.

Kraemer, B. D., Salisbury, S. B., \& Spielman, C. (1998). Pretreatment variables associated with treatment failure in a residential juvenile sex-offender program. Criminal Justice and Behavior, 25, 190-202.

Krug, E. G., Dahlberg L. L., Mercy, J. A., Zwi, A. B., \& Lozano, R. (2002). World report on violence and health. Geneva: World Health Organization.

Långström, N., Enebrink, P., Laurén, E-M., Lindblom, J., Werkö, S., \& Hanson, R.K. (2013). Preventing sexual abusers of children from reoffending: systematic review of medical and

psychological interventions. British Medical Journal, doi: 10.1136/ bmj. $\$ 4630$

Laws, D. R., \& Marshall, W. L. (2003). A brief history of behavioral and cognitive behavioral approaches to sexual offender treatment: Part 1: Early developments. Sexual abuse: A Journal of Research and Treatment, 15, 75-92.

Laws, D. R., \& O'Donohue, W. (2008). Sexual deviance: Theory, assessment, and treatment. New York: The Guilford Press.

Letourneau, E. J., Henggeler, S. W., Borduin, C. M., Schewe, P. A., McCart, M. R., Chapman, J. E., \& Saldana, L. (2009). Multisystemic therapy for juvenile sexual offenders: 1-year results from a randomized effectiveness trial. Journal of Family Psychology, 23, 89-102.

Letourneau, E. \& Miner, M. (2005). Juvenile sex offenders: A case against the legal and clinical status quo. Sexual Abuse: $A$ Journal of Research and Treatment, 17, 293-311.

Loeber, R., \& Farrington, D. P. (1998) (Eds.). Serious and violent juvenile offenders: Risk factors and successful interventions. Thousand Oaks, CA: Sage Publications

Lösel, F., \& Schmucker, M. (2005). The effectiveness of treatment for sexual offenders: A comprehensive meta-analysis. Journal of Experimental Criminology, 1, 117-146.

Marshall, W. L., \& Barbaree, H. E. (1990). An integrated theory of the etiology of sexual offending. In W. L. Marshall, D. R. Laws, \& H. E. Barbaree (Eds.). Handbook of sexual assault: Issues, theories and treatment of the offender (pp.257-275). New York: Plenum.
Marshall, W. L., \& Laws, D. R. (2003). A brief history of behavioral and cognitive behavioral approaches to sexual offender treatment: Part 2: The modern era. Sexual Abuse: A Journal of Research and Treatment, 15, 93-120.

National Task Force on Juvenile Sexual Offending. (1993). The revised report from the National task force on juvenile sexual offending. Juvenile and Family Court Journal, 44, 1-120.

Pawson, R., \& Tilley, N. (1997). Realistic evaluation. Thousand Oaks, CA: Sage Publications.

Seabloom, W., Seabloom, M. E., Seabloom, E., Barron, R., \& Hendrickson, S. (2003). A 14- to 24-year longitudinal study of a comprehensive sexual health model treatment program for adolescent sex offenders: Predictors of successful completion and subsequent criminal recidivism. International Journal of Offender Therapy and Comparative Criminology, 47, 468-481.

Sherman, L. W., Farrington, D. P., Welsh, B. C., \& MacKenzie, D. L. (2002). Evidence-based crime prevention. New York: Routledge.

Smallbone, S. (2006a). Social and psychological factors in the development of delinquency and sexual deviance. In H. E. Barbaree, \& W. L. Marshall (Eds.). The juvenile sex offender (2nd ed.) (pp. 105-127). New York: Guilford Press.

Smallbone, S. (2006b). An attachment theoretical revision of Marshall and Barbaree's (1990) Integrated Theory of the Etiology of Sexual Offending. In W. L. Marshall, Y. M. Fernandez, and L. E. Marshall (Eds.). Sexual offender treatment: Issues and controversies (pp. 93-107). Chichester, England: John Wiley and Sons.

Smallbone, S., \& Cale, J. (in press). An integrated life course developmental theory of sexual offending. In A. Blockland \& P. Lussier (Eds.). Sex offenders: A criminal careers approach. New York: Wiley.

Smallbone, S., Crissman, B., \& Rayment-McHugh, S. (2009). Improving therapeutic engagement with adolescent sexual offenders. Behavioral Sciences and the Law, 27, 862-877.

Smallbone, S., Marshall, W. L., \& Wortley, R. (2008). Preventing child sexual abuse: Evidence, policy and practice. Cullompton, Devon: Willan Publishing.

Smallbone, S., Rayment-McHugh, S., Crissman, B., \& Shumack, D. (2008). Treatment with youth who have committed sexual offences: Extending the reach of systemic interventions through collaborative partnerships. Clinical Psychologist, 12, 109-116.

Smallbone, S., \& Wortley, R. (2004). Criminal diversity and paraphilic interests among adult males convicted of sexual offenses against children. International Journal of Offender Therapy and Comparative Criminology, 48, 175-188.

Ward, T., \& Brown, M. (2004). The good lives model and conceptual issues in offender rehabilitation. Psychology, Crime and Law, 3, 243-257.

Ward, T., Yates, P., \& Willis, G. (2012). The good lives model and the Risk Needs Responsivity model: A response to Andrews, Bonta, and Wormith (2011). Criminal Justice and Behavior, 39, 94-110.

Willis, G., \& Ward, T. (2011). Striving for a good life: The good lives model applied to released child molesters. Journal of Sexual $\mathrm{Ag}$ gression, 17, 290-303.

Worling, J. (2004). Essentials of a good intervention programme for sexually abusive juveniles. In G. O'Reilly, W. L. Marshall, A. Carr, \& R. C. Beckett (Eds.). The handbook of clinical intervention with young people who sexually abuse. New York: Brunner-Routledge.

Worling, J. R., Litteljohn, A., \& Bookalam, D. (2010). 20-year prospective follow-up study of specialized treatment for adolescents who offended sexually. Behavioral Sciences and the Law, 28, 46-57.

Wormith, J. S., Gendreau, P., \& Bonta, J. (2012). Deferring to clarity, parsimony and evidence in reply to Ward, Yates and Willis. Criminal Justice and Behavior, 39, 111-120. 
Wortley, R., \& Mazerolle, L. (Eds.) (2008). Environmental criminology and crime analysis. New York: Routledge.

Wortley, R., \& Smallbone, S. (2006). Applying situational principles to sexual offenses against children. In R. Wortley, \& S. Smallbone (Eds.). Situational prevention of child sexual abuse (pp. 7-35). Monsey, NY: Criminal Justice Press.

Zimring, F.E. (2004). An American travesty. Chicago, IL: University of Chicago Press.

\section{- Author Contact Information}

\section{Stephen Smallbone, PhD}

Professor, School of Criminology and Criminal Justice,

Griffith University.

S.Smallbone@griffith.edu.au
Susan Rayment-McHug,h M.Psych

Griffith Youth Forensic Service - Neighbourhoods

Project

S.Rayment@griffith.edu.au

\section{Dimity Smith, BA Hons}

Griffith Youth Forensic Service - Neighbourhoods Project

D.Smith@griffith.edu.au 